\title{
Ways to Take Advantage of Knowledge Management in Jordanian Educational Institutions
}

\author{
Mahmoud Alnawaiseh ${ }^{1}$, Burhan Mahmoud Al-Omari ${ }^{1} \&$ Adnan Al-Rawashdeh $^{1}$ \\ ${ }^{1}$ Faculty of Management and Finance, The University of Jordan, Jordan \\ Correspondence: Mahmoud Alnawaiseh, Faculty of Management and Finance, The University of Jordan, Jordan. \\ E-mail: m.alnawaiseh@ju.edu.jo
}

Received: April 17, 2014

doi:10.5539/ijbm.v9n7p162

\author{
Accepted: May 8, 2014 \\ Online Published: June 22, 2014 \\ URL: http://dx.doi.org/10.5539/ijbm.v9n7p162
}

\begin{abstract}
This study aims To shed light on the concept of knowledge management and its dimensions, Understand the importance of knowledge management and justifications for taking out the institutions of higher education, To identify the input and knowledge management processes required for successful institutions of higher education, To identify the products and the effects of knowledge management institutions of higher education, Detection of the most important methods of benefit associated with the management of institutions of higher education knowledge.

The study used a descriptive approach to the appropriateness of the nature and objectives of the study; helps in the detection of the concept of knowledge management and its dimensions , processes and outputs of educational institutions, and that this approach does not stop at the present, but extends into the future, so do not stop at the borders describe phenomena and problems, but extends to the analysis and interpretation, and out of the conclusions meaningful benefit in the treatment of the issue under study. Conclusions private institutions of Arabic higher education: The analytical study revealed that higher education institutions in general, Arab, and in Jordan, and in particular suffer from, The absence of the concept of knowledge management and practices addressing the issues of knowledge in a piecemeal fashion, double the investment of modern technologies in the field of conservation and dissemination of information, lack of consensus skills and knowledge graduates with the requirements of the knowledge society, the weakness of the relationship between scientific research and knowledge management, with respect to the generation and dissemination of knowledge, need for higher education institutions to engage the Arab public in the era of knowledge and practices of knowledge management, through a good investment for intellectual capital available to them.
\end{abstract}

Keywords: knowledge management, educational institutions, utilization techniques, Jordan

\section{Introduction}

The evolution accelerated in communications and information technology at the present time to pay attention to the knowledge, in order to reach valuable knowledge, from the center of this vast amount of information which explode and accumulates daily, strengthened by the emergence of the World Wide Web "Internet " Internet, and breadth of applications in various areas of life. Which resulted in the emergence of many scientific concepts, such as knowledge management, and the knowledge economy and knowledge society, especially when I realized the educational institutions in higher education in Jordan that the interest in knowledge or intellectual capital is happening gears quality is enormous, and then began the search in the concept and practice of knowledge management, as one of the main entrances to help them overcome the challenges of the times, and to add value to compete and continue.

Perhaps this is what predicted by the "Toffler" Toffler, when he pointed out that the road to the "wealth and power" will begin by focusing on the work products of mental, whatever they contain of scientific research and technology, and the continuous training of the workforce in higher education, and to build and develop computer programs, and improve management systems and rely on sophisticated communication techniques in the completion of the work, and that the organization will become a vast field of competition and excellence, a private organization of knowledge itself and the good use. 


\section{Problem of the Study}

Form of knowledge management (KM) Balyatea and their contemporary twist of Information Management Information Management to Knowledge Management, where she was managing information maximize affair technological systems, as one of the most important elements of production, but today The management of knowledge consider the human element to it of the most important elements of that deal with information and technology, especially in the field of higher education, and then extends to all knowledge management processes that integrate with information, information technology and creative capabilities linked to humans.

Due to the importance of knowledge and management in the development of educational institutions and improve decision-making, creativity and speed of response to developments, came the title and content of the report of the World Bank for the year 98/1999 AD to carry this sense of "knowledge for development", and emphasizes that the way to bring about economic development and quality of concrete, at the level of institutions and communities, especially in developing countries like Jordan state, starts to knowledge management and sharing, by building a scientific base, and human brains attract highly skilled, and strengthen scientific research, and that this and that will not be achieved by human resources of high education and training.

The study of Musleeh (2007), confirms the benefits that can accrue to the Arab Universities of knowledge management, first and foremost find a source of self-financing, and the link between theory and practice, and then realizing the concept of the university produced. In addition, the knowledge management and operations help improve planning and decision-making of universities, and improving education and scientific research.

In spite of that, goes "Albalaoy, and Hussein" (2007) that there are a lot of obstacles to knowledge management in educational institutions in the Arab world, in absence of a clear vision of the concept of knowledge management and practices, and conflicting sources to obtain data and information, and the interpretation of the problems in person, and individual work a ways from the post in the knowledge of others, and the declining role of educational leadership in the adoption of an organizational culture that raises the value of knowledge and the value of participation, but also the value of creativity in the development of knowledge.

The study of "Knight" (2005) noted that the Jordanian universities face a lot of problems, which prevent the entry age of knowledge, and the ability to manage effectively, and that the low spending on scientific research and development, and then the low percentage of innovations and inventions needed to generate knowledge and develop.

While the study of "Turkish" (2007) showed that Jordanian universities do not give priority to knowledge management, as they do not have effective strategies to be implemented, but that the term knowledge management is not traded by the significantly, in terms of Egyptian private educational institutions, and according to "Mohammed" (2004) to the lack of these institutions to strategic planning, knowledge management, poor use of information technology, and the presence of unambiguous and ambiguity in the concepts and practices relating to the management of knowledge.

In general, some interested in issues goes to higher education Arab nationalist, and from the Egyptian university and education that there are a lot of obstacles that may limit its ability to achieve effective management of knowledge, and is an indicator at the same time to the weakness of exercising them, including:

-Poor infrastructure and management and leadership.

-Lack of clarity of vision for the educational and research programs that need to be asked

- Failure in cooperation and partnership with the community institutions that can be useful in the acquisition of knowledge and exchange.

-The lack of ability to face competition from other institutions offering educational and training services of high quality, and the saturation of the needs of a lot of categories.

-Lack of consensus skills and knowledge of the outputs of university education system with the requirements of the labor market changing and evolving

-Weakness to exploit information and communication technology in the field of conservation and dissemination of information.

-Deficiencies in the provision of knowledge sources necessary for scientific research.

-The lack of scientific researches cumulative, which rely on tracking the achievements of previous research and add to it, including helping to organize knowledge and evolution. 
-The declining role of university libraries in front of digital libraries, the libraries are still largely dependent on the method of paper in keeping information and knowledge dissemination; affecting its role as a vital source of knowledge and scientific research.

-Need disciplines of library and information to the university courses own systems, databases, programming and information networks and communication technology?

-The declining role of the university in the service of the community, both in providing qualified human resources, or in scientific research work associated with the reality or the provision of technical consultancy and specialized management, which reflects the abuse of the university to its supplier (human).

-Poor adherence to the values inherent university, and except dialogue, and constructive criticism, and collective action, and other elements of the exchange of knowledge and experiences, and increase the capacity for development and innovation.

Accordingly, look to the needs of Arab universities in general, and Jordanian universities, particularly to reconsider the structure and built a new philosophy, to promote methods benefit from data communication revolution and information and the entrance of knowledge management, as set forth in that reconsidered in scientific disciplines existing building educational programs developed, and the adoption of a corporate culture directed strongly towards the promotion of scientific research, and realize the importance of knowledge management to improve this or that, and activate their own operations, the formation and organization, dissemination and application, etc., especially in light of an era of increasing knowledge and accumulate, and heightened competition and rising, which is a whole to improve the performance of the universities, and improve their ability to compete and survive.

In light of the above problem this can be formulated in the study of the following questions:

Q1: What is the concept of knowledge management and its dimensions in management thought and contemporary educational?

Q2: What is the input of knowledge management and operations of the institutions of higher education?

Q3: What are the outputs of knowledge management institutions of higher education?

Q4: What methods take advantage of the knowledge management institutions of higher education?

Q5: What recommendations and proposals needed to make better use of knowledge management institutions of higher education in Jordan?

\subsection{Objectives of the Study}

The study aimed to achieve the following:

- To shed light on the concept of knowledge management and its dimensions.

- Understand the importance of knowledge management and justifications for taking out the institutions of higher education.

- To identify the input and knowledge management processes required for successful institutions of higher education.

- To identify the products and the effects of knowledge management institutions of higher education.

- Detection of the most important methods of benefit associated with the management of institutions of higher education knowledge.

- Provide a set of recommendations and suggestions that can help to take advantage of knowledge management institutions of higher education in Jordan.

\subsection{Importance of the Study}

Launch scientific and practical importance for the study of several aspects of the current societies that is:

The need to shed light on the concept of knowledge management, on the grounds that modern concepts relatively, which addressed many of the areas from different angles, resulting in some of the mystery and the public in the eating, which may improve the ways of practice in higher education institutions.

- The importance of the topic that addresses the study to be treated ; where knowledge management is the most important day of the ins and tools that affect the success of the institutions, which highlights the need to detect the most important operations and practices and products . 
- Also kicks off the importance of the study of the importance of the university educational institution ; institution where it is cognitive in nature, and in the forefront of the knowledge -producing institutions and distributed them at once, which forces them to take advantage of knowledge management in upgrading its functions.

- Scarcity of Arabic studies that dealt with knowledge management in educational institutions in general, and in particular university, then it may contribute to the study in the enrichment of knowledge in this area, as it may be a prelude to other studies in the field of education.

- Help stakeholders and decision-makers in Arab university in general, and in particular the Jordanian universities, in the detection of the dimensions of knowledge management and practices, as may support the trend towards application and use it to achieve the functions of the university assigned to them efficiently and effectively.

\section{Methodology}

The study used a descriptive approach to the appropriateness of the nature and objectives of the study ; helps in the detection of the concept of knowledge management and its dimensions, processes and outputs of educational institutions, and that this approach does not stop at the present, but extends into the future, so do not stop at the borders describe phenomena and problems, but extends to the analysis and interpretation, and out of the conclusions meaningful benefit in the treatment of the issue under study.

The study relied on systems theory The System Theory, which looks at anything on that system, System, and that this system seeks to achieve a goal or specific targets, and consists of a set interactive input. Inputs, and Operations Processes, and outputs Products, which are affected by each other and the system total constituent positively or negatively, note that this system works in the context of the environment or open field, as it can be seen as a subsystem of a larger system of it. Then it can be considered as knowledge management system consisting of a set of inputs, processes, outputs, or is a subsystem of the larger university system as yarmouk university and university of Jordan, each have more than 35 thousand students,, and so on, and are therefore affected by the domain in which it operates or by the ocean.

\subsection{Terms of the Study}

\section{- Utilizing methods: Utilization Techniques}

Intended methods utilize "procedural" in the current study "group practices and improvements in administrative and technical organization, people enter the university on aspects of their different work when the management of knowledge and implementation of its operations, which have achieved at the same time effective investment to knowledge resources available, and to enable them to meet the challenges and investment opportunities present and future".

\section{- Knowledge Management (KM)}

Goes Leo Liew (2007) was writing, that the concept of knowledge management is one of the concepts that can be any intra- field or scientific discipline taken, which may explain the mystery and confusion about the concept in this context, is defined by Althbyta (2004) knowledge management as the framework within which to consider the institution from which to operations as cognitive processes, those processes for the production and distribution of knowledge, update, and use, it is also interested in those processes that organize, direct and control all the business of the Corporation.

The focus of Alali, and others (2006) on the knowledge that bring added value, so when workers look at knowledge management as critical knowledge management, which rely on the knowledge base, which aims to achieve added value for the business, through the processes of the operation which includes the diagnosis and the acquisition of generating ideas, storing and development, distribution and application of knowledge available to the institution, in documents and databases or in the minds of their employees.

While this was discussed by both Albiloy, and Hussein (2007) as a knowledge management as they defined it, and by considering it as a knowledge management to strengthen the administrative processes, and includes the management activities and process such as: the use and distribution of knowledge, with the aim of strengthening organizational knowledge base, and any new knowledge management and assessment of the current knowledge.

In the framework of optimal investment of intellectual capital and improve the performance of the university, known as defined by Musslah (2007) Knowledge management in the university institution as a process designed to possess the ability to develop and invest the intellectual capital of the university, through the cognitive 
processes of diagnosis and the generation, storage and the development of knowledge and distribution, and its applied in various administrative activities, which increases the productivity of the university.

\section{By looking to the previous definitions of knowledge management, we can notes the following:}

-Totally agree to the importance of knowledge management to improve the performance of institutions in general or in particular universities.

-Their interest in knowledge management operations, which emphasizes the role of these processes in the success of knowledge management.

-Differ on the number of processes involved in the management of knowledge in the denominations.

-Repeated for a number of operations, which generate, store, distribute and apply knowledge, demonstrating the vitality of these processes in knowledge management.

-Overlooked the determinants of input or knowledge management, and then double the linkage between management and knowledge.

In light of the above, can be defined as knowledge management (KM), procedural in the current study as a system composed of a set of humanitarian inputs, administrative, technological, and a set of processes systemic represented in the diagnosis of knowledge and identify their goals, and their generation, storage, distribution and application which seeks to be developed

And the development and exploitation of knowledge and property expertise and technology available to the University, in problem-solving and decision-making and building plans and strategies, which will leads to improve the services provided by the universities, and enable the Universities to continue the competition . "

\section{- Educational Institutions}

Some argue that the concept of educational institutions refers to those institutions which have specialized functions in a systematic process in education and education without other jobs, and that schools and universities, as it is those institutions that members specially prepared to do the teaching profession.

And goes Albaloy, and Hussein (2007) that the term institutions is used to describe the social processes that occur on a regular frequent basis, which are preserved through customs and social values and traditions, and then "all insinuations" is the process by which become social areas reality, and occur repeatedly and continuously, until the application description applied to all institutions.

It then means "educational institutions" procedural "in the current study" those academic institutions that specialized systematically in teaching, scientific research and community service, located at the top of the educational ladder, and degree granting certain, expressing the possession of their owners capabilities and knowledge required to work or specialization in a particular professional field. They are also those institutions that make up a vital source of knowledge production, dissemination and application, and social development continued.

\section{- Operations or process}

Intended to "procedural" in the current study "set of actions and activities, administrative and technical irregular, carried out by the university to achieve good knowledge management available to all managers, which includes the diagnosis of knowledge, and to identify their goals, and the generation and acquisition, storage, distribution, and application".

\section{- Outputs}

Intended to "procedural " in the current study " the benefits and positive effects that can be achieved by the university, which is reflected on its educational programs, research and service, through the exercise of knowledge management, which appear to improve the performance of its functions, and raise the level of performance of the year"

\subsection{Previous Studies}

Resulted in the survey of the studies of Arab and foreign studies which meant the subject of the current study, a number of studies that focused on knowledge management in institutions of higher education and universities and education in particular, in addition to some of the studies that have focused on combining academic institutions and institutions of productivity when discussing the issue of knowledge management.

That can be addressed as follows:

The first axis: studies focused on knowledge management in institutions of higher education and universities. 
Study of Jennifer (2000);

Study of Chaudhry, and Higgins (2001);

Study of Benjamin, and others (2003);

Study of Kauks (2003);

Study of Kelly (2004);

Study of Kumar, and Kumar (2006);

Study of McCarthy (2006);

Study of Brianj \& Taspunj (2007);

Study of: Althbyta (2004);

Study of Alsaeed. Muhammad (2004);

Study of Turky(2005);

Study of Mussleah(2007);

\subsection{Comments on Previous Studies}

Through a review of previous studies, Arab and foreign studies, it is clear that there are similarities and differences in benefit between the current study and previous studies, can be addressed as follows:

\subsubsection{Similarities}

The current study confirm as the previous studies on the vital role that can be played by knowledge management for educational institutions and universities, from the development of the universities administration, and improve planning and decision-making of universities, and the development of of education systems and scientific research, and the use of modern technologies, so as a study Turkish (2007), and the study of " Muslleah (2007) and the study of Kelly Keeley (2004), and the study of Kumar and kumar (2006).

Other studies those are similar to the current study, with the most of the previous studies in their approach to knowledge management in the field of higher education. Another study that similar to the current study with some previous studies in analytical study it, and so as a study, Migdal (2005) and the study of the Fares (2005), and the study Beasley, and Cooper Beesly \& Cooper (2008).

This study is agreed to the current foreign study and Arabic Studies, in need of Arab universities to revisit continually in the curriculum content and scientific research systems and management, to suit the requirements of knowledge management and the needs of the labor market, and that as a study of Althbyty (2004), and the study of Mussleah (2007), and the study Turky (2007).

This study is agreed to the current study with some previous studies in the presence of unequivocal and public in the concept of knowledge management, and the need to further study and analysis, especially in educational institutions, and so as a study Turky (2007), and the study of Beesly \& Cooper (2008) .

\subsubsection{Differences}

The current study differs from previous studies in their approach to knowledge management as an integrated system, in its inputs, processes and outputs. And exposed to the current study of knowledge management institutions of higher education in Jordan, unlike previous studies, with the exception of the study of Alssaed and Mohammed (2004), and these differ in their objectives and orientations.

This study examines the current methods to take advantage of the universities and it is contemporary knowledge management, which was not the focus of previous studies and, there is lack of focus of the current study on knowledge management in institutions of production and business, like some previous studies, such as studying of Migdal (2005), and the study of Beesly and Cooper (2008).

\subsection{Aspects of the Benefits}

The current study benefited from previous studies in several aspects, namely:

- Determine the general framework and theoretical basis of the current study.

- Disclosure of the concept of knowledge management and its dimensions.

- Benefit from the findings and recommendations of previous studies. 


\section{Conclusions}

Through previous analytical study of knowledge management in educational institutions in general, including private and public universities, this includes a set of conclusions that can be addressed as follows:

The follows are the finding and concept of knowledge management and its evolution as.

-The knowledge institutions that seek to get them, is in two main forms: the explicit knowledge, such as those in their documents and databases, and tacit knowledge, and skills of its human resources, which constitute the core of the intellectual capital.

-The existence of the early beginnings of the concept of knowledge management practices in the Arabic era, to be known as Bhawwanat Aloraganieen libraries or contemporary sense.

-The emergence of the scientific roots of the concept of knowledge management in the nineteenth century by the schools of thought in management, scientific research.

-That the real attention to knowledge management back to the nineties of the twentieth century, as a result of developments in the cognitive, technical and economic .

-The lack of agreement among scientists on the precise definition of the concept of knowledge management, as a result of the breadth of the areas covered by this concept and the different perception of the nature of knowledge itself, and then manage the entrances.

-That the concept of knowledge management can be seen as a system consisting of inputs, processes and outputs, and aims to provide the knowledge needed to make decisions and solve problems and plan to any university.

-There is a need and a global trend towards the adoption of the concept of knowledge management practices and, as a result of developments in the cognitive, economic, technical and maximize the return on intellectual capital.

-That the good prognosis of knowledge by selecting the educational institution what they need to know what they own, is the main premise towards defining the goals of knowledge management accurately, and then the success of the various operations and take advantage of them.

-The acquisition of knowledge as a process of knowledge management processes, does not stop at the borders for educational institution from internal and external sources, but also to innovation and generation.

-That the process of applying knowledge and take advantage of them is the goal and purpose of knowledge management, and then administration knowledge is a means and not an end.

Third, the conclusions of the private institutions of knowledge management outcomes of university of education:

Knowledge management has helped the contemporary of any university:

-The development of the university administration and support decision-making processes.

-Establishing a culture of teamwork and the sharing of knowledge, creativity and innovation.

-Property Investment in the cognitive development of educational curricula and research and development of activities.

-Increasing the ability of the parties to work on campus to face problems.

-Increased job satisfaction and belonging to the University Foundation.

-A good investment for intellectual capital available to the University.

-Reduce the cost of university operations.

-The internationalization of university services.

-Access to value-added and competitive advantage.

\section{The findings of special methods to take advantage of knowledge management:}

-That university or institutions rely heavily on modern techniques in the diagnosis of knowledge and define its objectives, and maps the expert knowledge and scanning the internal and external performance and trends .

-The direction of universities toward fundamental changes in the structures and the structures and processes to fit in and knowledge management.

-That there is continued support for the role of scientific research in the process of knowledge generation and acquisition. 
-The trend towards the development and expansion of existing libraries in digital libraries to support the acquisition and dissemination of knowledge

-The expansion of the university in contemporary partnerships and alliances with counterpart institutions and non- corresponding to the exchange and dissemination of knowledge.

-Adopting the university contemporary advanced educational patterns, such as distance education and e-learning, helping to spread knowledge and get added value.

-Exploitation of the World Wide Web Internet in the distribution and exchange of knowledge.

-Expansion of departments and scientific disciplines relevant science and information technology, libraries and systems, as a way of helping to adapt to the demands of the knowledge society and the labor market .

-Oriented curricula associated networks and modern techniques.

-The direction of the contemporary of university to support the link between scientific research and productive enterprises.

Conclusions private institutions of Arabic higher education:

The analytical study revealed that higher education institutions in general, Arab, and in Jordan, and in particular suffer from:

-The absence of the concept of knowledge management and practices.

-Addressing the issues of knowledge in a piecemeal fashion.

-Double the investment of modern technologies in the field of conservation and dissemination of information.

-Lack of consensus skills and knowledge graduates with the requirements of the knowledge society.

-The weakness of the relationship between scientific research and knowledge management, with respect to the generation and dissemination of knowledge.

-Need for higher education institutions to engage the Arab public in the era of knowledge and practices of knowledge management, through a good investment for intellectual capital available to them.

\section{Recommendations and Proposals}

In the framework of the objectives of the study and its results, researcher can apply a set of recommendations and suggestions to improve methods that can take advantages of the knowledge management in education institutions in Jordanian universities in the following manner:

Recommendations of the study:

First, the recommendations relating to inputs of knowledge management belong to educational insinuation in Jordan:

A. Spreading the culture of knowledge management which includes:

-Uphold the value and importance of knowledge in the academic aspects of the work.

-Support the value of teamwork, in order to facilitate the acquisition and dissemination of knowledge.

-To emphasize that the importance of knowledge and its value lies in the dissemination and use, and not to keep.

-Develop programs to stimulate occasion that encourages creativity and innovation at work.

-Activate the media role of the university in promoting a culture of knowledge management.

B. The development of structures and organizational structures, which includes:

-Review structures of scientific disciplines in the context of the principle of unity and integration of knowledge.

-To strengthen horizontal communication, allowing the flow of knowledge and the spread between the parties and units of university work.

-Continuous training of the various parties to the university work, in the use of information and communication technologies and their applications.

-Rely on teams to work in diverse disciplines of doing business, in order to facilitate the generation and application of knowledge.

-Switching to electronic university administration, helping to speed the collection and dissemination of information. 
C. Providing the necessary infrastructure for knowledge management which includes:

Building bases of information and knowledge and linked to local area networks and the World Wide Web.

Building an advanced technology centers in collaboration with institutions with expertise.

Provide computers for sections and units of university units.

To provide the necessary funding to build the technological infrastructure and knowledge.

D. The development of the role of university leadership, which includes:

-University leadership adopted the concept of knowledge management and a commitment to its practices.

-Invent new methods and techniques that will develop the knowledge base.

-Opening up to foreign institutions in the framework of knowledge management.

-To encourage teamwork and stimulate creativity and innovation.

-Spreading the culture of knowledge management through leadership model example.

-Spread the culture of organizational learning and embrace change.

-To provide appropriate mechanisms to measure the skills of individuals in the context of knowledge management.

The recommendations related to the operations of knowledge management:

A. The diagnosis of knowledge:

-Develop clear strategies to determine the cognitive assets owned by the university.

-Rely on knowledge in the diagnosis of knowledge management applications, Kniz experience and knowledge maps.

-Building organizational structures for knowledge resources.

-Gather the necessary information about the relevant institutions and the needs of the community.

B. The process of identifying the objectives of knowledge:

-Support the ability of the parties to work on campus to deal with techniques and knowledge management systems.

-Review of knowledge included in the curriculum and their suitability for the knowledge society.

-Review the activities and the activities of scientific research and how it relates to knowledge management.

-Support for external orientation toward the internationalization of the service within the university system and a clear knowledge management.

-The pursuit of value-added and get the competitive advantage of university services.

C. The process of generating knowledge:

-Creating the right climate to support the role of scientific research in the production of knowledge and development.

-Develop plans for organization of the partnership and cooperation with counterpart institutions and non- debate, to support the generation of knowledge and the formation and distribution.

-Find regulator in knowledge bases to local area networks and the World Wide Web.

-Expansion in conferences, seminars, meetings and workshops, scientific, for the benefit of the acquisition and sharing of knowledge and experiences.

-Emphasis on the role of organizational learning in the acquisition and dissemination of knowledge.

D. The process of storing knowledge:

-Develop clear and specific mechanisms for storing knowledge and organized according to their own priorities in university decision support.

-Information obtained by purification and formulation in the form of usable.

-Support the role of the university library in keeping knowledge and retrieval.

-Standardization of terminology and evidence of work related to the management of knowledge, in all university departments and units. 
-Linking stores and warehouses of information and knowledge systems, advanced connectivity, including easy retrieval when needed.

E. The distribution of knowledge:

-Using the method of a difference in the distribution of knowledge and knowledge between units and departments at the university.

-The drafting of reports and academic guidance, in the form of enabling the dissemination of knowledge.

-The expansion of scientific disciplines and educational programs, associated with the library and information science.

-Sophisticated design sites on the World Wide Web and periodically updated, including helping to distribute and disseminate knowledge.

-Emphasis on the role of the patterns of distance education in the dissemination of knowledge.

And the process of applying knowledge:

-Using the knowledge gained in the daily work of the Foundation of any University.

-Development of systems allows effective applications for knowledge management.

-Use of available knowledge in the development of the educational process.

-Instill the concept of multiple sources of knowledge among the university community.

-Developing the capacity of students to use information and communication technologies.

-Promote teamwork skills to work with the parties to the university.

-Take advantage of the information and knowledge gained from the teachers, in the development of the university system.

-To exploit the available knowledge in the development of processes and scientific research activities, for the benefit of the development of knowledge and recycled.

-Expansion of advisory services based on knowledge.

-The exploitation of knowledge management and technology in the internationalization of university service.

\section{References}

Althbyta, J. M. (2004). Programs of Computer Science and Information Systems and libraries in Saudi universities in the light of the scientific framework for knowledge management and knowledge-based economy.

Beesly, L. G. A., \& Cooper, C. (2008). Defining Knowledge Management (KM) Activities: Towards Consensus. Journal of Knowledge Management, 12(3).

Coukos, S. E. (2003). Knowledge Management in Research Universities: The Processes and Strategies, Paper Presented at The American Educational Research Association Annual Meeting, Chicago.

Jennifer, R. (2002). Is Higher Education Ready for knowledge Management? Journal of Educational Management, 14(7).

Kaweevisultrakul, T., \& Chan, P. (2007). Impact of Cultural Barriers on Knowledge Management Implementation: Evidence from Thailand. Journal of American Academy of Business.

Keeley, E. J. (2004). Institutional Research as the Catalyst for The Extent and Effectiveness of Knowledge Management Practices in Improving Planning and Decision Making in Higher Education Organizations.

Knight. (2005). Knowledge Management and Innovation: Where Arab universities of these developments? Symposium: Strategic Management in Higher Education Institutions

Kumar, A., \& Kumar, A. (2006). IT Based KM in Indian Higher Education Systems: Addressing Quality Concerns and Setting The Priorities Right. Journal of Knowledge Management Practice, 4(4).

Liebowitz, J. (1999). Key Ingredients to the Success of an Organization's Knowledge Management Strategy. Knowledge and Process Management, 6(1), 37-40.

Lim, K., Pervaiz, A., \& Zairi, M. (2000). The Role of Sharing in Knowledge Management Initiatives. Working Paper, No. 0005. Bradford: Management Centre University of Bradford 
Majdal, A., \& Houari, A. (2005). Managing Organizational Knowledge in institutions of higher education: the concept, methods and strategies. Symposium: Strategic Management in Higher Education Institutions, held at King Khalid University, in cooperation with the Arab Organization for Administrative Development.

McCarthy, A. F. (2006). Knowledge Management: Evaluating Strategies and Processes Used in Higher Education. Ph.D., Nova Southeastern University, Publisher Proquest Informational Learning Co.

Mentzas, G., Apostolou, D., Young, R., \& Abecker, A. (2001). Knowledge Networking: A holistic solution for leveraging corporate knowledge. Journal of Knowledge Management, 5(1), 94-106

Morse, R. (2000). Knowledge Management Systems: Using Technology to Enhance Organizational Learning. Information Resources Management Association (IRMA), International Conference, Anchorage, Alaska.

Moss, G. (2007). Knowledge Management in Higher Education: A Comparison of Individualistic and Collectivist Cultures, European. Journal of Education, 42(3).

Musleah, J. (2007). Knowledge Management: An Introduction to achieve a model of university-produced.

Nonaka I., \& Konno, N. (2000). The Concept of "ba": Building a Foundation for Knowledge Creation. In Hermans, J. (Ed.), The Knowledge Management Yearbook 1999-2000 (pp. 37-51). USA: Butterworth-Heinemann.

Nonaka, I., Umemoto, K., \& Senoo, D. (1996). From Information Processing to Knowledge Creation: The Knowledge-Creating Company. Technology in Society, 18(2), 203-218.

Penjamin, L. (2003). Appling Knowledge Management in University Research. Ph.D., Singapore Management University.

Pervaiz, A., Lim, K., \& Zairi, M. (1999). Measurement Practice for Knowledge Management. Bradford: University of Bradford.

Prayong, T. \& Tasapong, K. (2007). Knowledge Management is A Perfect Education Development Tool: is Thailand's Higher Education Really Ready to Embrace it? Journal of Knowledge Management Practice, $8(2)$.

Radding, A. (1998). Knowledge Management; Succeeding in the Information-based Global Economy.

Santosus, M., \& Surmacz, J. (2001). The ABCs of Knowledge Management.

Sayed, A. F. Q., \& Mohammed, M. A. (2004). A proposed model for the role of knowledge management in an information society in educational institutions.

Seubert, E., Balaji, Y., \& Makhija, M. (2001). The Knowledge Imperative.

Shaudhry, A., \& Higgins, S. (2001). Perspectives on Education for knowledge Management. Paper Presented at The 65th IFLA Council and General Conference. Boston.

Skyrme, D. (2001). Knowledge Strategy Development. Retrieved from $\mathrm{http}: / /$ www.skyrme.com/services/kmstrat.htm

Snowden, D. (2000). A Framework for Creating a Sustainable Knowledge Management Program. In Hermans, J. (Ed.), The Knowledge Management Yearbook 1999-2000 (pp. 52-64). USA: Butter worth-Heinemann.

Turky, Y. A. (2007). Knowledge management and the possibility of their application in Saudi Universities: An Empirical Study on the Umm Al Qura University.

\section{Copyrights}

Copyright for this article is retained by the author(s), with first publication rights granted to the journal.

This is an open-access article distributed under the terms and conditions of the Creative Commons Attribution license (http://creativecommons.org/licenses/by/3.0/). 